\title{
Application of new balloon catheters in the treatment of congenital heart defects
}

\author{
Roland Fiszer ${ }^{1}$, Małgorzata Szkutnik², Linda Litwin², Sebastian Smerdziński ${ }^{1}$, Beata Chodór ${ }^{1}$, Jacek Białkowski² \\ ${ }^{1}$ Department of Congenital Heart Diseases and Pediatric Cardiology, Silesian Center for Heart Diseases, Zabrze, Poland \\ 2Department of Congenital Heart Defects and Pediatric Cardiology, School of Medicine with the Division of Dentistry in Zabrze, \\ Medical University of Silesia, Katowice, Poland
}

Adv Interv Cardiol 2016; 12, 3 (45): 231-237

DOI: 10.5114 /aic.2016.61645

\begin{abstract}
A bstract
Introduction: Balloon angioplasty (BAP) and aortic or pulmonary balloon valvuloplasty (BAV, BPV) are well-established treatment options in congenital heart defects. Recently, significant technological progress has been made and new catheters have been implemented in clinical practice.

Aim: To analyze the results of BAP, BAV and BPV with the new balloon catheter Valver and its second generation Valver II, which the company Balton (Poland) launched and developed. These catheters have not been clinically evaluated yet.

Material and methods: We performed 64 interventions with Valver I and Valver II. With Valver I the following procedures were performed: 17 BPV (including 9 in tetralogy of Fallot - TOF), 10 BAV and 27 BAP in coarctations of the aorta (CoA) - including 9 native and 18 after surgery. With Valver II ten interventions were done - 3 BPV, 2 pulmonary supravalvular BAP (after switch operations), 2 BAP of recoarctations and 3 other BAP. Age of the patients ranged from a few days to 40 years.

Results: All procedures were completed successfully, without rupture of any balloon catheters. The pressure gradient drop was statistically significant in all groups: BPV in isolated pulmonary valvular stenosis $28.1 \mathrm{~mm} \mathrm{Hg}$ (mean), BPV in TOF $18.7 \mathrm{~mm} \mathrm{Hg}$, BAV $32.8 \mathrm{~mm} \mathrm{Hg}$, BAP in native COA $15.4 \mathrm{~mm} \mathrm{Hg}$ and in recoarctations $18.6 \mathrm{~mm} \mathrm{Hg}$. In 3 cases during rapid deflation of Valver I, wrinkles of the balloons made it impossible to insert the whole balloon into the vascular sheath (all were removed surgically from the groin). No such complication occured with Valver II.
\end{abstract}

Conclusions: Valver balloon catheters are an effective treatment modality in different valvular and vascular stenoses.

Key words: congenital heart defects, balloon angioplasty, aortic coarctation, balloon valvuloplasty, pulmonary valve stenosis, aortic valve stenosis.

\section{Introduction}

Balloon angioplasty (BAP) and pulmonary or aortic balloon valvuloplasty (BPV, BAV) are well-established treatment options in congenital heart defects. Pulmonary valvuloplasty and in the majority of cases aortic valvuloplasty are the methods of choice (as definitive or palliative procedures) [1, 2]. Moreover, balloon angioplasty is the main complementary method to classical surgery in native coarctation and recoarctation of the aorta after an operation [3, 4]. Significant technical and material progress has been made recently, and new balloon catheters have been implemented in clinical practice. To the best of the authors' knowledge, Valver catheters' usefulness in congenital heart defects has not been clinically evaluated yet.

\section{Aim}

This publication aims to analyze the results of balloon valvuloplasty and angioplasty with the new balloon catheter Valver and its second generation Valver II, which the company Balton (Warsaw, Poland) launched and developed.

\section{Material and methods \\ Study population}

We analyzed the results of BPV, BAV and balloon angioplasty performed in a single tertiary center from January 2011 to July 2015. During this period, 64 patients underwent procedures with a Valver balloon catheter, including 10 procedures performed with Valver II. We distinguished six groups of interventions. Five of them

\section{Corresponding author:}

Linda Litwin, Department of Congenital Heart Defects and Pediatric Cardiology, Silesian Center for Heart Diseases, M. Curie-Sklodowskiej 9 , 41-800 Zabrze, Poland, phone: +48 3227134 01, e-mail: litwinlinda@gmail.com

Received: 15.09.2015, accepted: 13.01.2016. 
were performed with Valver I: BPV in patients with tetralogy of Fallot (TOF; 9 patients) (mainly newborns), BPV in isolated pulmonary valvular stenosis (8 patients), BAV (10 patients), angioplasty in native coarctation of the aorta (9 patients), and angioplasty in recoarctation of the aorta after surgery (18 patients). The last group (10 patients) contained different interventions (valvuloplasty and angioplasty) performed with the second generation catheters - Valver II. All diagnoses were supported by transthoracic echocardiography and confirmed during the diagnostic catheterization preceding the interventional procedure. Age of patients varied from a few days to 40 years. Fifty-five percent of patients were male. Informed consent was obtained from all patients (or their parents).
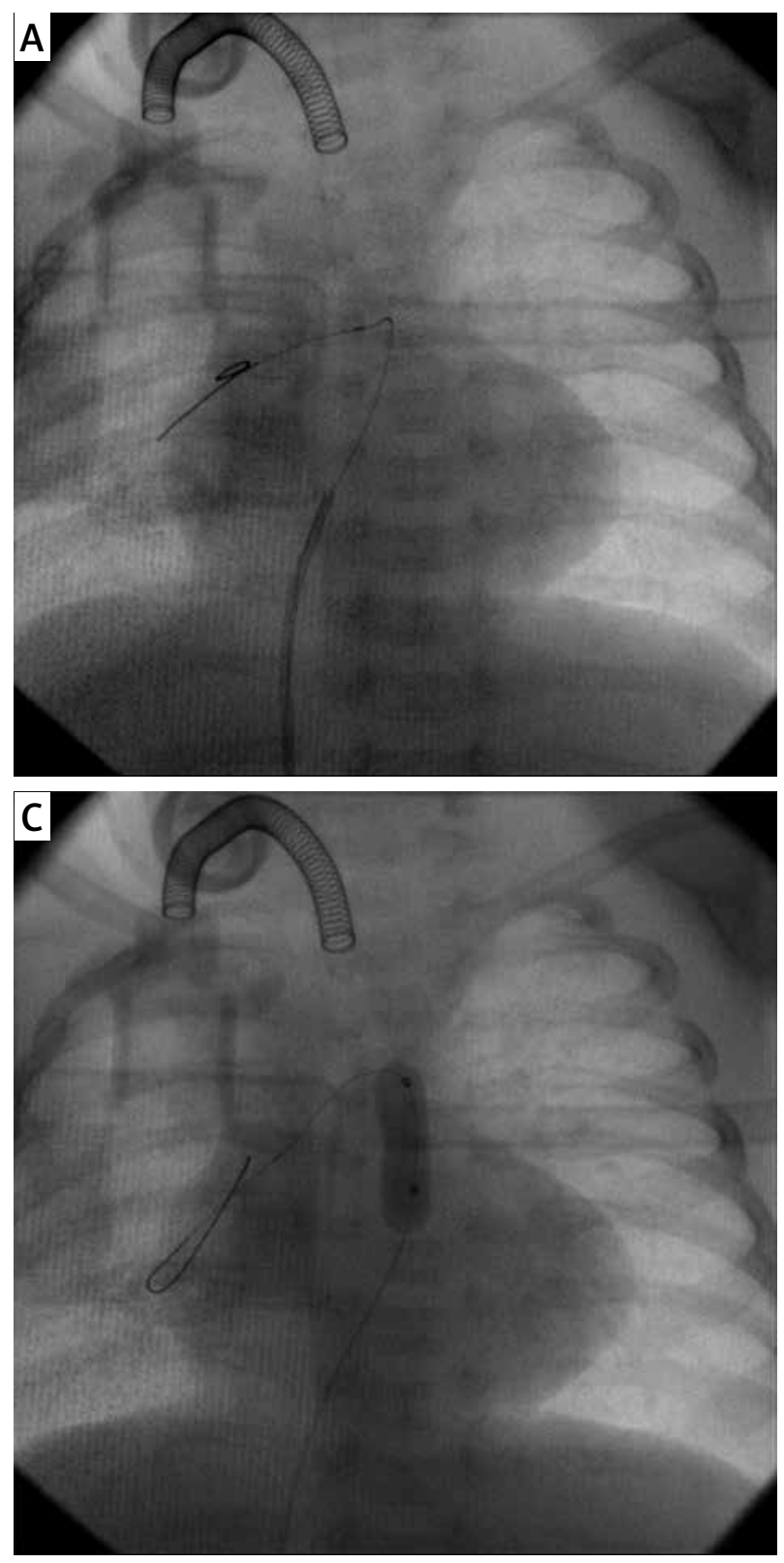

\section{Device description}

Valver balloon catheters (Balton, Warsaw, Poland) have been certified with the CE mark and have gained a marketing authorization valid throughout the European Union since 2008. They are available in different sizes (the diameter of balloons ranges from 5 to $35 \mathrm{~mm}$ and length from 2 to $6 \mathrm{~cm}$ ) and are compatible with $0.021-$ $0.038 \mathrm{~mm}$ guidewires and 4-14 Fr introductory sheaths. They are low profile and low pressure balloons (for example, nominal balloon diameter $8 \mathrm{~mm} /$ length $2 \mathrm{~cm}$ requires shaft diameter $4 \mathrm{~F}$, guidewire 0.018 , its nominal pressure is $2 \mathrm{~atm}$, rated burst pressure (RBP) $5 \mathrm{~atm}$, average burst pressure (ABP) $7 \mathrm{~atm}$, and nominal balloon diameter $12 \mathrm{~mm}$ /length $2 \mathrm{~cm}$ requires $5 \mathrm{Fr}$ shaft guidewire 0.022 , its nominal pressure is $2.5 \mathrm{~atm}, \operatorname{RBP} 5 \mathrm{~atm}$ and

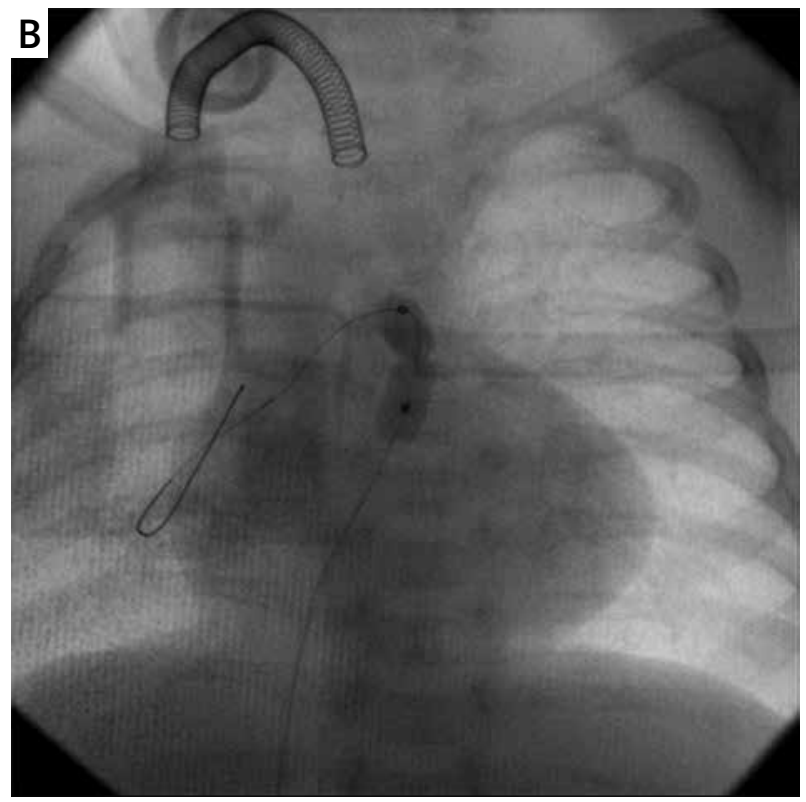

Figure 1. Balloon pulmonary valvuloplasty in an infant with tetralogy of Fallot and respiratory failure, after tracheotomy - procedural steps: A - passing through a stenotic valve using the guidewire, $\mathbf{B}$ - Valver balloon catheter inflation at the level of a valvular ring (the waist on the balloon is still visible), $\mathbf{C}$ - disappearance of the waist proving the effectiveness of the intervention 
ABP 8 atm). Generally, according to the manufacturer's information the nominal pressure ranges from 2 to $3 \mathrm{~atm}$ and the burst pressure from 4 to $5 \mathrm{~atm}$. The second generation of devices was launched and implemented in our cathlab in April 2015. The difference in construction of the two catheters is that in Valver I there are 2 concentric canals (external dedicated for inflation and deflation and internal for guidewire), while Valver II catheters possess 2 separate canals, which preserves the deflation function of this balloon.

\section{Interventional procedure}

Intervention techniques were similar to methods described previously in the literature $[5,6]$. Technical details of the BPV procedure in a child with TOF are presented in Figure 1.

We introduced balloon catheters through nominal or +1 Fr introductory sheaths. Our team analyzed trans-vessel or trans-valvular gradients before and after the procedure in all patients as well as vessel diameters in angioplasty groups. Immediate success was defined as: a residual pulmonary gradient $<36 \mathrm{~mm} \mathrm{Hg}$ in pulmonary stenosis in TOF cases, a residual gradient across the aortic valve $<50 \mathrm{~mm} \mathrm{Hg}$ with no aortic regurgitation grade III or IV in aortic valvular stenosis, a residual trans-aortic gradient $<20 \mathrm{~mm} \mathrm{Hg}$ in coarctation or recoarctation of the aorta and/or $>50 \%$ decrease in pressure gradient following the procedure. The success rate and complications were evaluated in all patients as well as clinical and technical aspects of applied balloon catheters.

\section{Statistical analysis}

Pre- and postprocedure pressure gradients were analyzed with the Wilcoxon signed-rank test. $P$-values $<0.05$ were considered to be statistically significant.

\section{Results}

All interventions were performed successfully without any rupture of the applied Valver type I or II balloons. Details of procedures performed with Valver II are presented in Table I.

Two groups of patients underwent BPV (isolated pulmonary valvular stenosis and pulmonary stenosis in TOF), and the pressure gradient decreased statistically significantly in both (Figure 2). In isolated pulmonary valvular stenosis (median age: 1.9 years; from 3 weeks to 40 years) the mean pressure gradient drop was 28.1 $\pm 19.3 \mathrm{~mm} \mathrm{Hg}$, from 0 to $57 \mathrm{~mm} \mathrm{Hg}(p<0.03)$, in comparison to $18.7 \pm 8.7 \mathrm{~mm} \mathrm{Hg}$, from 10 to $39 \mathrm{~mm} \mathrm{Hg}$ ( $p<$ 0.009 ), in patients with TOF (median age: 0.2 years; from 5 weeks to 16 years).

We achieved satisfactory results with hemodynamically irrelevant mild pulmonary stenosis $(<31 \mathrm{~mm} \mathrm{Hg}$ ) in 5 patients with isolated pulmonary valvular stenosis. In 2 patients intervention was ineffective due to valvular dysplasia. One of them, a 7-month-old infant, was finally treated surgically. In another patient with suprasystemic pressure in the right ventricle (a 40-year-old woman) the procedure was only partially effective initially because of the advanced form of pulmonary stenosis - right ventricle hypertrophy. This patient had after BPV an immediate pressure gradient decrease from 163 to $103 \mathrm{~mm} \mathrm{Hg}$. A subsequent gradual gradient fall was observed in follow-up in transthoracic echocardiography after $\beta$-blocker treatment. It was probably due to reduced right ventricle hypertrophy, which was responsible for subvalvular components of this stenosis.

Immediate success was achieved in $11 \%$ of patients with pulmonary stenosis associated with TOF. But, what is more important, we observed increased saturation and better development of pulmonary artery branches in patients with TOF after BPV - documented in Figure 3.

In patients with aortic valvular stenosis (median age 0.4 years; from 1 day to 5 years) the results were varied and depended on valve morphology and dysplasia. Aortic regurgitation is a well-known complication of BAV and was present in 3 of our patients after the intervention (stage I in 2 patients, stage II in 1 patient). The mean pressure gradient drop was $32.8 \pm 24 \mathrm{~mm} \mathrm{Hg}$, from 3 to $72 \mathrm{~mm} \mathrm{Hg}(p<0.002)$, and the immediate success rate was $90 \%$ (Figure 4 ).

Similarly, the effectiveness of intervention in patients with coarctation (native or post-surgical) was dependent on the morphology of the aorta. Both groups of patients who underwent angioplasty of the aorta had a significant pressure gradient decrease. In the native variant of coarctation (median age: 3 years; from 1.5 to 9.5 years) the mean drop was $15.4 \pm 13.4 \mathrm{~mm} \mathrm{Hg}$, from 2 to $47 \mathrm{~mm} \mathrm{Hg}$ $(p<0.004)$, and immediate success was achieved in $66.7 \%$ of patients.

In the post-surgical variant of coarctation (median age: 0.7 years; from 3 months to 11 years) the mean change of gradient was $18.6 \pm 13.3 \mathrm{~mm} \mathrm{Hg}$, from 0 to $44 \mathrm{~mm} \mathrm{Hg}$ ( $p<$ 0.0006 ), with a $72.2 \%$ immediate success rate (Figure 5 ).

The new generation balloon catheter (Valver II) was launched in April 2015. To date, 10 patients have undergone intervention with this device (Table I). This group includes different procedures: 3 BPV in isolated pulmonary valvular stenosis, 2 BPV in pulmonary supravalvular stenosis in patients after arterial switch operation, 1 angioplasty of an anastomosis between the right atrium and pulmonary artery in a patient after a hemi-Fontan operation (patient no. 5 in Table I), 1 angioplasty in recoarctation of the aorta after surgery, 1 redilatation of the stent in recoarctation of the aorta, 1 angioplasty of pulmonary artery branch stenosis after surgical repair of common arterial trunk type I (patient no. 8 in Table I) and 1 debanding of the pulmonary artery after a Norwood I operation (patient no. 6 in Table 1). Detailed data are summed up in Table I. All BPV in patients with isolated 


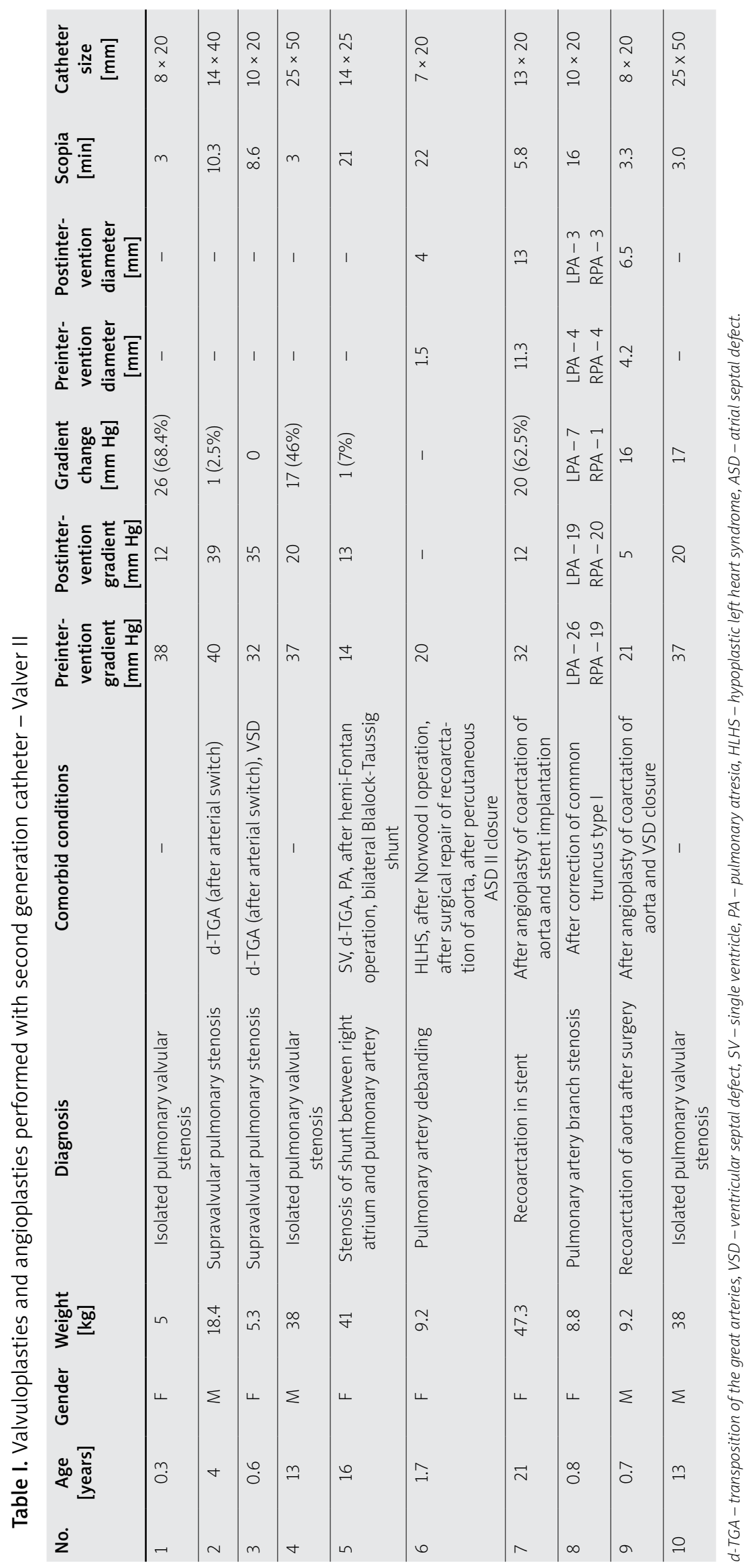




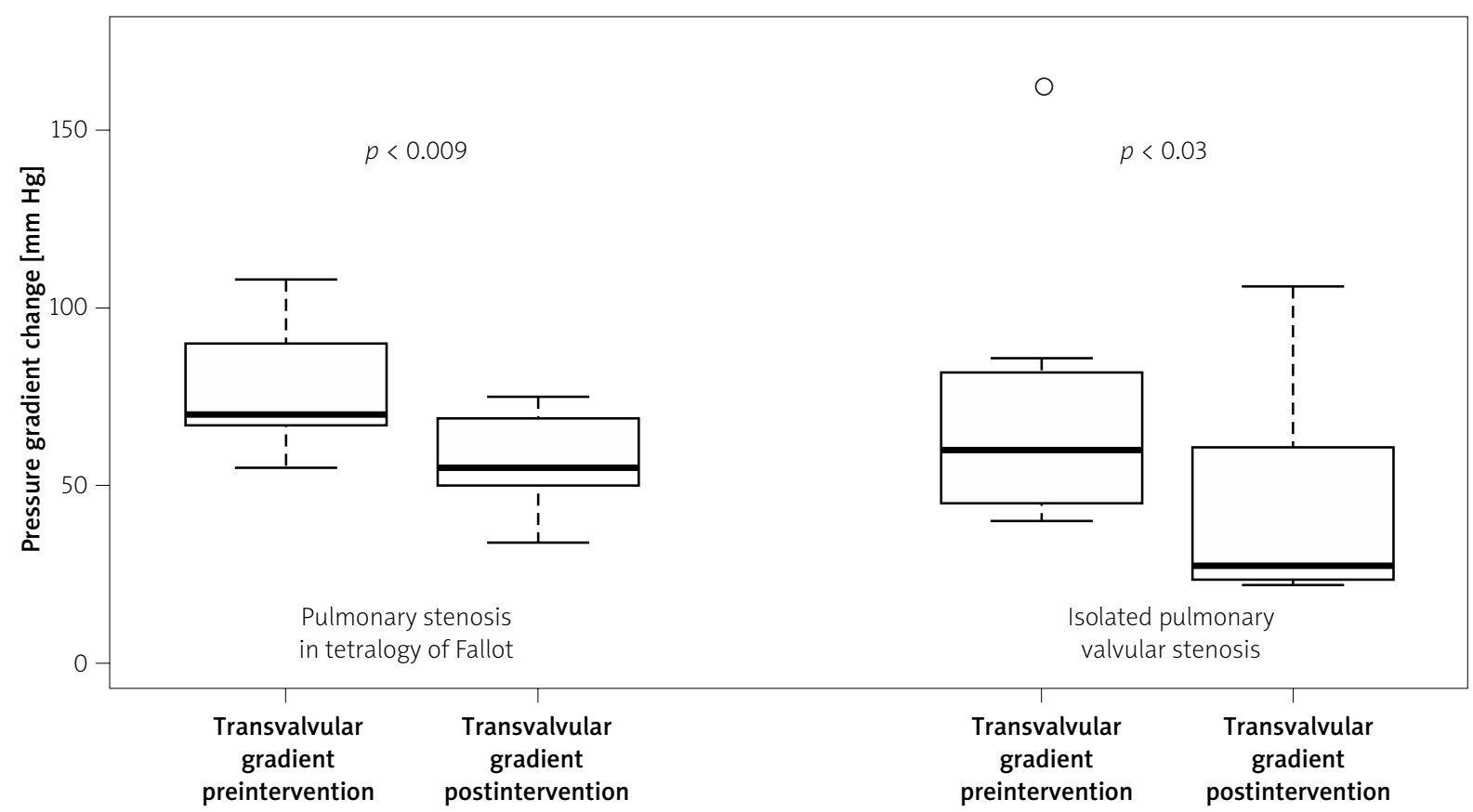

Figure 2. Pressure gradient change after BPV in pulmonary stenosis in tetralogy of Fallot and isolated pulmonary valvular stenosis
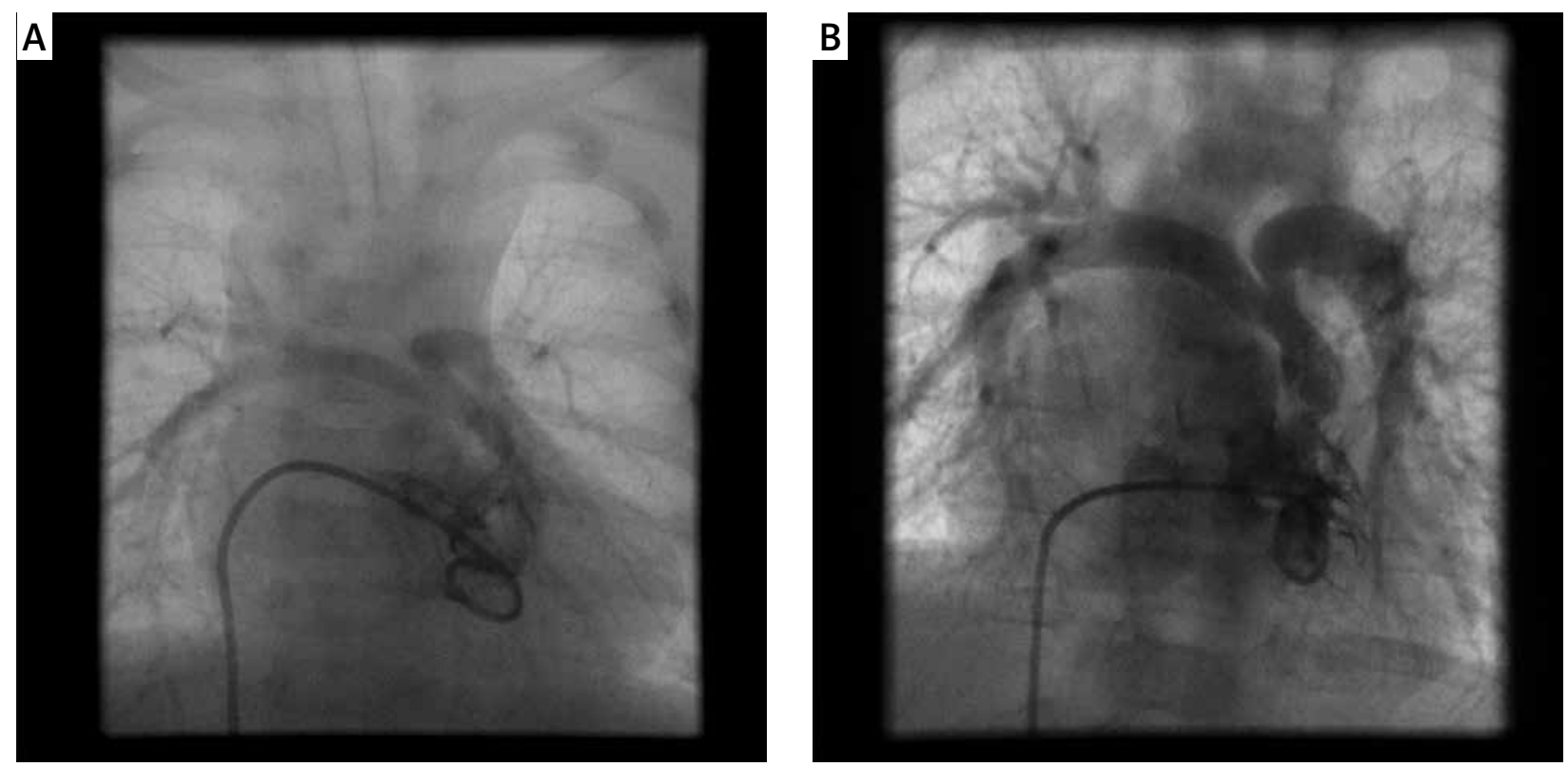

Figure 3. Right ventriculography with pulmonary artery imaging in an infant with tetralogy of Fallot: $\mathbf{A}-$ at 5 months of age, before BPV - distinct hypoplastic pulmonary artery branches; B - 4 months after BPV - significantly wider valve annulus and better developed pulmonary artery branches

pulmonary valvular stenosis, BAP in recoarctation of the aorta after surgery, dilatation of the stent in recoarctation of the aorta and the debanding procedure were successful. Other procedures in this group were atypical interventions and should not be compared to other results.

According to operators' opinions, inflation of Valver I balloons was comparable to other devices. Balloon deflation in Valver I should be done slowly and with cau- tion, otherwise wrinkles may appear at the surface of the balloon. This complication occurred in 3 cases during rapid deflation with tightening of the catheter. It caused inability to put a deflated balloon (making it impossible to inflate or deflate the mass) into the introductory catheter and was a reason for surgical intervention of the wrinkled, collapsed balloon. One arteriotomy of the femoral artery (in a ReCoA case) and two vein sections 


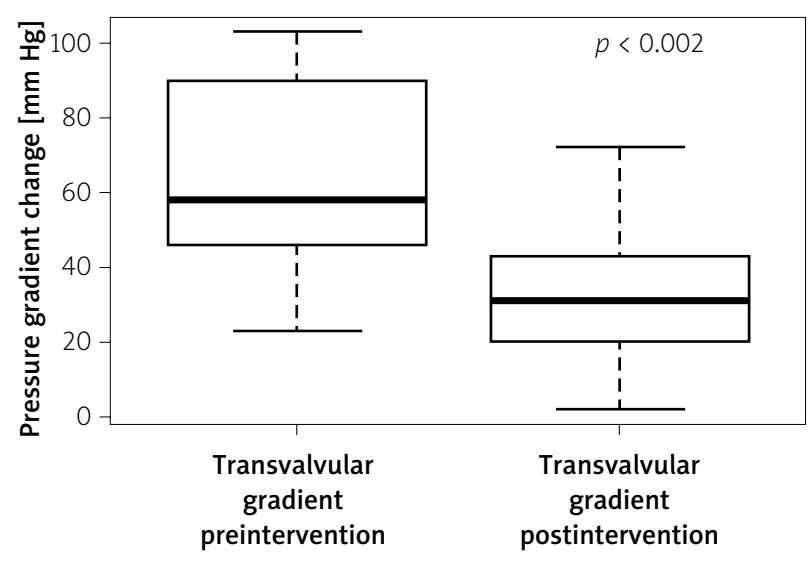

Figure 4. Pressure gradient change after BAV

were necessary (one in a case of ReCoA done from vein access and one in a case of pulmonary BPV). No inflation or deflation difficulties were noted with Valver II. According to the manufacturer's information, in both catheters (Valver I and II) inflation and deflation time "in vitro" was the same.

\section{Discussion}

The results indicate the clinical usefulness of the new Valver balloon catheters. A low profile and a short inflation time are important features of these catheters. These properties were highlighted during a live intervention at the $4^{\text {th }}$ Vietnam Congress of Congenital and Structural Heart Disease in Ho Chi Minh City in January 2014 [7]. Unfortunately, during the next Vietnam Congress, "Right ventricular outflow tract intervention" in January 2015, in one among 3 live cases performed with Valver I balloon catheters (all BPV) the operator was unable to retrieve the balloon into the introductory sheath after rapid deflation. According to our knowledge, the new model of the Valver II catheter is free from its forerunner's disadvantages. There were no difficulties with Valver II balloon inflation, deflation or retrieval in our group of patients. This was probably related to the new construction characteristics of Valver II balloons, described briefly above in the section "Device description". Effectiveness of BPV and BAV in long-term follow-up is confirmed by recent publications [8-10]. Moreover, our research gives validity to BPV in children with tetralogy of Fallot as a palliative intervention [11]. We assume that the good result of procedures with Valver and Valver II catheters will continue in the long-term observation. We plan to continue the follow-up as part of our future research. The results of balloon angioplasty in coarctation of the aorta (native and post-surgical) also prove Valver's clinical usefulness. The effectiveness of other balloon catheters in coarctation of the aorta was also documented in the literature [12]. The efficacy of Valver catheters in pulmonary artery branch stenosis was questionable (data not presented in this publication). This could be due to the Valver's characteristics with nominal pressure of 2-3 atm. Higher effectiveness was suggested with high pressure balloon catheters in these cases [13]. Our study is limited by the small number of patients and lack of randomized comparisons to different balloon catheters. To the best of the authors' knowledge, we have provided a new insight in the field, as there are no data available on Valver catheters' usefulness in congenital heart defects.

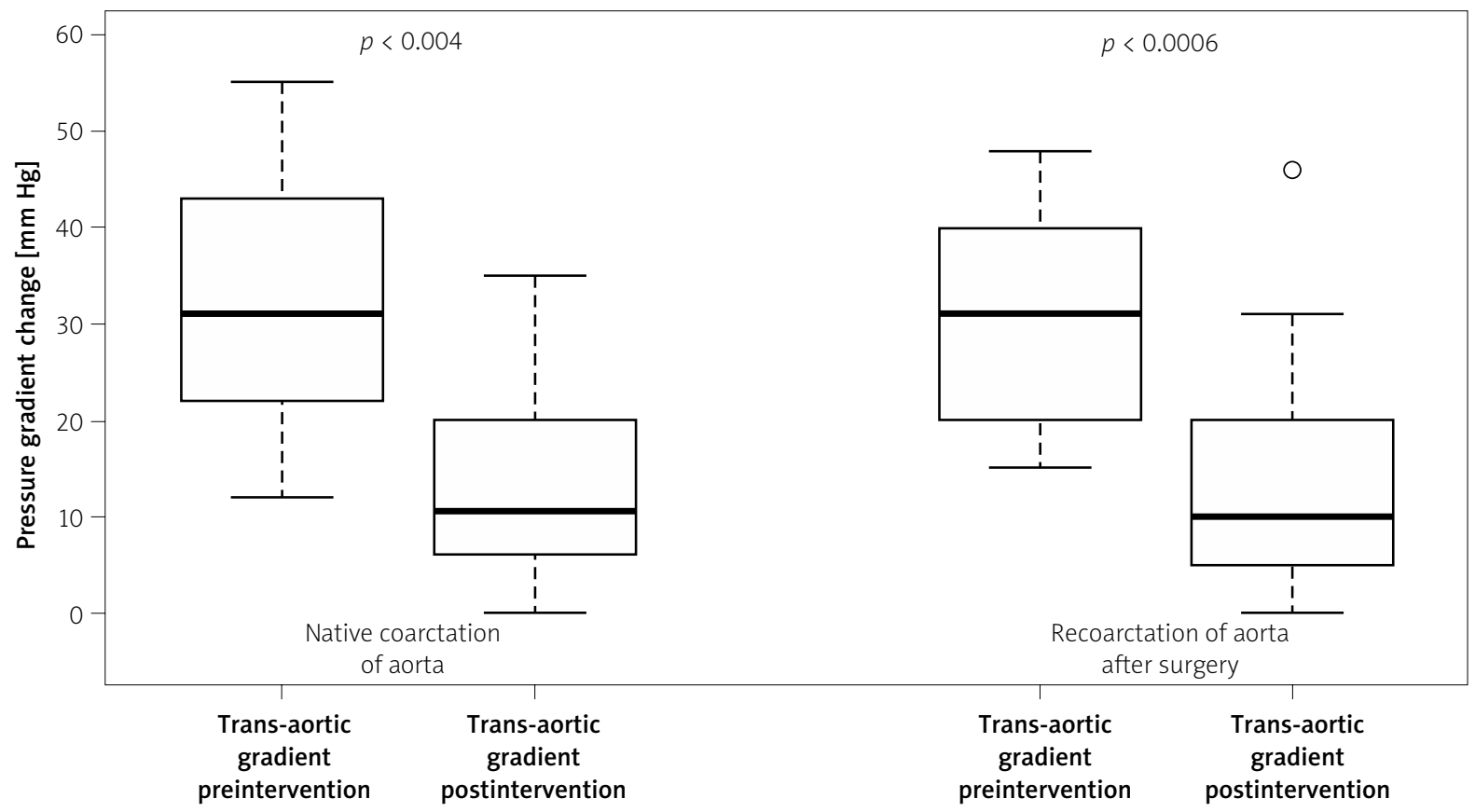

Figure 5. Pressure gradient change after angioplasty in native and post-surgical coarctation 


\section{Conclusions}

Valver balloon catheters are an effective treatment modality in different valvular and vascular stenoses.

\section{Conflict of interest}

The authors declare no conflict of interest.

\section{References}

1. Holzer RJ, Gauvreau K, Kreutzer J, et al. Safety and efficacy of balloon pulmonary valvuloplasty: a multicenter experience. Catheter Cardiovasc Interv 2012; 80: 663-72.

2. McElhinney DB, Lock JE, Keane JF, et al. Left heart growth, function, and reintervention after balloon aortic valvuloplasty for neonatal aortic stenosis. Circulation 2005; 111: 451-8.

3. Ammar RI. Balloon angioplasty for native aortic coarctation in children and infants younger than 12 months: immediate and medium-term follow-up. J Invasive Cardiol 2012; 24: 662-6.

4. Dilawar M, El Said HG, El-Sisi A, et al. Safety and efficacy of low-profile balloons in native coarctation and recoarctation balloon angioplasty for infants. Pediatr Cardiol 2009; 30: 404-8.

5. Moore P, Lock JE. Catheter interventions: balloon angioplasty. In: Diagnostic and interventional catheterization in congenital heart disease. Lock JE, Keane JF, Perry SB (eds.). Kluwer Academy Publishers, Boston, Dordrecht, London 2000; 119-50.

6. Yeager SB, Flanagan MF, Keane JF. Catheter interventions: balloon valvotomy. In: Diagnostic and interventional catheterization in congenital heart disease. Lock JE, Keane JF, Perry SB (eds). Boston, Dordrecht, London: Kluwer Academy Publishers 2000; 151-78.

7. Bialkowski J. Report from the $4^{\text {th }}$ Vietnam Congress of Congenital and Structural Heart Disease $\left(8^{\text {th }}-10^{\text {th }}\right.$ January 2014 , Sajgon, Vietnam) - "Fistulas from A to Z". Kardiochir Torakochirurgia Pol 2014; 11: 353-5.

8. Merlino-Ingelmo R, Santos-de Soto J, Coserria-Sanchez F, et al. Long-term results of percurtaneous balloon valvuloplasty in pulmonary valve stenosis in the pediatric population. Rev Esp Cardiol (Engl Ed) 2014; 67: 374-9.

9. Maskatia S, Ing F, Justino $\mathrm{H}$, et al. Twenty-five year experience with balloon aortic valvuloplasty for congenital aortic stenosis. Am J Cardiol 2011; 108: 1024-8.

10. Garty Y, Veldtman G, Lee K, et al. Late outcomes after pulmonary valve balloon dilatation in neonates, infants and children. J Invasive Cardiol 2005; 17: 318-22.

11. Kreutzer J, Perry SB, Jonas RA, et al. Tetralogy of Fallot with diminutive pulmonary arteries: preoperative pulmonary valve dilatation and transcatheter rehabilitation of pulmonary arteries. J Am Coll Cardiol 1996; 27: 1741-7.

12. Harris KC, Du W, Cowley CG, et al. A prospective observational multicenter study of balloon angioplasty for the treatment of native and recurrent coarctation of the aorta. Catheter Cardiovasc Interv 2014; 83: 1116-23.

13. Gentles TL, Lock JE, Perry SB. High pressure balloon angioplasty for branch pulmonary artery stenosis: early experience. J Am Coll Cardiol 1993; 22: 867-72. 